\title{
The Changes of Ru Skirt in Tang Dynasty Under the Influence of Buddhist Culture*
}

\author{
Ting Zhang \\ School of Art \\ Xi'an International Studies University \\ Xi'an, China
}

\begin{abstract}
Ru skirt is the basic style of women's dress in Central Plains as well as one of the casual clothes of the Tang Dynasty. Its inheritance of the tradition of native Han Chinese Clothing has not been interrupted, but unprecedented changes have taken place in the process of fusion of foreign cultures carried by Buddhism from the west. This kind of change not only has the breath of Greek human body aesthetics, but also has the imprint of cultural integration of Confucianism, Buddhism and Taoism and the human nature expression under the feudal system and the information which the scene expresses. The integrated round, natural, and sexy romantic style is the Tang people's expression to the ideal beauty in the figure plastic arts. This article combs the development of Buddhism in China's Tang Dynasty, and then discusses the influence of the process of Buddhism eastward on the Ru skirts of the Tang Dynasty, and expounds the Buddhist cultural implications in the changes in the skirts and its reasons.
\end{abstract}

\section{Keywords—Tang Dynasty; skirts; Buddhism}

\section{INTRODUCTION}

The most prestigious character shape in the Tang Dynasty is the shape of woman's Ru skirt. The exposed beauty of the body art and the modeling characteristic of loving bright-colored clothing are unprecedented like mystery. Because this phenomenon does not have historical inheritance, it has caused the guessing and exploration of many scholars. Wang Qiming believes that this is because of the cultural exchange between the Tang Dynasty and other ethnic groups; Xiao Xiao'en believes that this is influenced by $\mathrm{Hu}$ people from Central and Western Asia; Dr. Na Chunying believes that this is the result of the awakening and practice of ancient Chinese women's consciousness, and some scholars believe that this is because the rulers of the Tnag dynasty have the bloodline of the Xianbei ethnic minorities in the north and their acceptability is better. More scholars believe that the political and economic foundations of the Tang Dynasty have sufficient conditions to allow people to break through the ban to pursue individuality. The author believes that under the influence of the ritual foundation of Zhou Dynasty and the traditional influence of Confucianism, the objective conditions are not enough to form such a trend. Only the internal strength that satisfies the spiritual needs of subject and can reach the ideological

*Project: Xi'an International Studies University Teaching Reform Research Project (No. 17BYG36) consensus of the group can create such special situation. An important source that makes convergence and interpretation in historical time, spiritual sustenance, and aesthetic guidance is the influence of Buddhism in the Tang Dynasty of China. As a foreign culture, Buddhism not only coexists with traditional Confucianism and Taoism in the land of the Central Plains through the power of culture to culture, but also affects the social life of different levels of the Tang Dynasty up and down in politics, economy and art by the advantage of filling the gaps in the spirit. This has important significance for explaining the culture of the Tang Dynasty and revealing the spiritual meaning of the characters in the Tang Dynasty.

\section{BRIEF DESCRIPTION OF BUDDHISM DEVELOPMENT IN TANG DYNASTY}

In $2 \mathrm{BC}$, Buddhism was introduced into China in the first year of Yuan Shou of the Western Han Dynasty. It was selfevolving when it spread in the Central Plains in small scope. The lack of grounding did not set off a climax of belief. In the middle of the 1 st century $\mathrm{AD}$, with the emergence and rise of Mahayana Buddhism, Buddhism in Gandhara completed the transition from abstract visualization without idol to figurative iconography. During the period from the Sixteen States to the Weijin period (304-589 AD), Buddhist statues rose in China. With the emergence and influence of the idol worship entity, the presence of feelings is bound to increase, and Buddhism has begun to develop rapidly in China.

According to historical data, Buddhism in the Sui and Tang Dynasties was supported by the royal family and ushered in an unprecedented flourishing period. Following the favor of the Emperor of Sui Dynasty, the Tang Dynasty provided the social policies and material conditions for the full flourish of Buddhists. During the Emperor Taizong of Tang period (627-649 AD), Confucianism and Taoism were used as the basis of governing the country, but it also gave opportunities for the joint development of Buddhism. Taizong of Tang Dynasty used the example of the emperor Wudi of the Liang dynasty who lost the country because of favor of Buddhism as the lesson, and adopted conservative acceptance attitude to Buddhism. At the same time, he also realized the role and value of Buddhism in the rule of the world. Although he didn't make vigorously construction, he 
also helped the dissemination of Buddhism and translation of Dharma. After the Emperor Taizong of Tang Dynasty, there are devout believers in the royal family of the Tang Dynasty. Therefore, they supported the construction of Buddhist temples, worshiped Buddhist monks, promoted the monastic economy, and adopted the taboos of the Buddhist scriptures to the regulation of Tang Dynasty to push the development of Buddhism to its peak. Gaozong Lizhi and the Empress Wu Zetian also did this, and Buddhism became the state religion during the two administrative periods (AD 650-705). Later Zhongzong and Ruizong of Tang Dynasty also paid attention to Buddhism, which led to the formation and improvement of eight major Buddhist sects. With advanced ideology and religious philosophy, Buddhism promoted the deep belief of the entire society in the Tang Dynasty to worship Buddhas. Not only was the official respected, but the people also were even more enthusiastic. For a time, the nation made donation and opening cave and building status became a common practice. During the Xuanzong Period (AD 712-756), the Buddhist power expanded to touch the order and interests of the imperial power. The related restrictive institutional policies were successively introduced to curb the accumulation of money in Buddhist temples and discussion of weal and woe that impede feudal rule. However, this kind of governance is not eradicative, but it only strengthened the management and guidance of Buddhism development and its attitude towards Buddhism remains positive. At the end of the Xuanzong period, An Lushan Rebellion (AD 755-763) broke out. The development of Buddhism began to decline as the Tang Dynasty was hit hard by warfare, and sectarianism faded successively. During the Wu Zong period (841-846 AD), based on the differences between Buddhism and Confucianism and its influence on the economics of imperial power, the movement of exterminating the Buddhism was carried out during the Huichang period. Since then, Buddhism has not returned to its former prosperity in the ancient Chinese feudal society.

Although Buddhism prospered in the Tang Dynasty and eventually declined in the Tang Dynasty, Buddhism was successfully implanted in the Central Plains during the prosperous period before the Middle Tang Dynasty, achieved class penetration from top to bottom, and the theoretical thought of Buddhism was popularized and spread. The number of believers has grown large enough. Buddhism not only served for Tang social education but also was promoted by Tang politics. Therefore, it maintained a close relationship with the Tang Dynasty. During the development of Buddhism in the Tang Dynasty, due to excessive expansion that jeopardized the order of the feudal rule and the interests of the ruling class, the Tang dynasty had implemented various prohibition-limiting tactics and even initiated the campaign to eliminate the Buddhism in different periods. The suppression of interweaving has not stopped, but overall among the more than a dozen emperors of the entire Tang Dynasty, many believe and respect Buddhism, making Buddhism, this foreign religion develop jointly with Confucianism and Taoism development, and once become the lead of the three religions. Even if war and the movement of Buddhism destruction hit it and its spirits no longer existed, until the late Tang Dynasty, the public believers in
Buddhism remained unyielding and passionate. Buddhism eventually succeeded in completing its localization in China, and religious influences were incorporated into all aspects of social life.

\section{INFILTRATION OF BUDDHIST CULTURE IN RU SKIRTS}

The doctrines of Buddhism including that rewards for good and evil, eternal cycle of birth and death, and the mercy have filled the world with a wider space of ideas beyond Confucianism and Taoism, and become the sustenance of people's spirit and vision. In addition, features of Buddhism such as the flexible theory, convenience for worshiping at home make it very easy to promote and infiltrate, so Buddhism quickly conquered the majority of believers, especially female followers.

The doctrines of Buddhist such as mercy and leniency and helping all life beings are more in line with the characteristics of women's softness and purity, and are easily accepted by women. In spite of the social opening up and economic prosperity of the Tang Dynasty, coupled with the influence of the Queen We Zetian, women's status has improved somewhat, women have a certain degree of freedom of belief, and women's social life quality has also improved, but all of them are relative. It is the appearance under the feudal system since traditional rituals still bound women's activities and taking care of the family is still women's duty. In order to help female worship Buddhism in the feudal system, the Buddha statues were also transformed from masculinization to femininity in the Tang period, which greatly facilitated the social infiltration of Buddhism. The way of believing in Buddhism including becoming a nun and practicing at home gave women a way to recognize themselves, their souls and spirits in the feudal rituals, and find their way and choice to their destination. Therefore, the number of female followers rapidly expanded.

As an important carrier for the representation of plastic arts, female groups are the creators and leaders of plastic arts. The social culture and aesthetic tendencies are reflected in women's activities, female labors and their production. Therefore, the aesthetic tastes and intentions of women in the Tang Dynasty played an important role are in the development and change of $\mathrm{Ru}$ skirts. The Buddhist aesthetics and its artistic elements are also incorporated into the daily dresse $\mathrm{Ru}$ skirt and its matching makeup, decoration and other life details with the women's belief in the Buddha and the activities of worshiping the Buddha, which further influences the overall aesthetic thought of the Tang period.

From the remains of the Tang dynasty grotto murals, ancient tomb murals and scroll figures, it is also possible to peek into the performance of the Buddhist culture and the Western cultural elements it absorbed and carried in Tang Dynasty figures. 


\section{THE CHANGE OF RU SKIRT AND EXPRESSION OF BUDDHISM IMPLICATION IN TANG DYNASTY}

Clothing, as the largest proportion of the figure model with the most obvious features, is the core of modeling design, as well as the basis for modeling analysis. There is no lack of the influence of Buddhist art in the Ru dress of the Tang Dynasty. It is common in the forms, colors, decorative patterns and so on.

\section{A. Buddhist Implications in the Shape of Ru Skirt}

In the 1st century AD, Mahayana Buddhism emerged in the Gandhara region of the ancient Indian border and Buddha sculptures appeared, giving Buddhism the image of a Buddha that the public could worship. The Gandhara combines the native culture of India with the influence of the Greek culture brought about by the invasion of the Alexandrian Empire, which makes the carving art present the characteristics of the Indian local decorative line method and the hybrid Greek style method. The Greek sculpture gives God a human image, simple yet elegant and refined, pursuing the body's structural lines and muscular bodybuilding, while Indian native carvings highlight decoration. Although the artistic style of the combination of the East and the West of the Gandhara was not as strong as that of India's indigenous Mathura and became fading, both arts entered the Chinese territory with the spread of Buddhism. In addition, when Buddhism traveled along the Silk Road to the east, it also absorbed the body art of the local people when it passed through China's Kuchi and Gaochang in Xinjiang, which combined to affect the Central Plains. The development of Buddhism in the Tang Dynasty was prosperous and the Ru skirts drew on the aesthetics and decorative techniques of the human body from Buddhism culture, especially statues and paintings, and put on the changes in the style and aesthetics ideas of Ru skirts.

The Ru skirt is the dress with short top and long dress, which is commonly called the tops and skirt. In Tang Dynasty, women's Ru skirts basically include three-piece suits: skirts, blouses and jackets. They wear short jackets or blouses on the top and long skirts with tippet. After Kaiyuan, women in the Tang Dynasty wore Ru skirts with unprecedented sexiness, the height of waistband was gradually lift, and clothing became lighter and lighter. Some skirts were covered with a tube top (ie Bra) and some made the female's breast obvious. With the light yarn outside, making the skin expose indistinctly. The exoticism of Buddha's exposing breast, arms and waist presents the spirit of esteem for human body and the pursuit of free and flowing aesthetics in the Tang dynasty under the feudal system in China, which is expressed in the process of gradually expanding nature and revealing of the $\mathrm{Ru}$ skirts. From this, it can be seen that the style of Ru clothing in Tang Dynasty gradually embodied the human perspective and the visual sensation of fullness, roundness, and gracefulness was the ideal beauty characteristic of the combination of Buddhist art.

\section{B. Religious Implications in Colors of Ru Skirt}

The color of Chinese ancient costumes has a distinctly philosophical concept of the five elements of the local religious Taoism. For example, black represents the water in the five elements and Qin like black, which was used to extinguish the fire of the Zhou Dynasty. With the operation of five elements, the Han Dynasty preferred the fire, so the Han Dynasty began to praise red. However, the color of clothing in the Tang Dynasty didn't seem to be limited to the previous five-element theory from monochrome to binary color and multiple colors. It also breaks the taboos of traditional customs from time to time, which is not only a gesture of social openness, but also inspired and influenced by Buddhist culture to a great extent. . For example, white clothes are called plain clothes. Ancient people wear white linen shirts for serving the dead. Therefore, white has always been regarded as an ominous color, and folks avoid wearing white clothes for the whole body. In the Buddhist art, the dentary of the Buddha are white, which represents the purity of the Dharma, and implies a kind of relief. It symbolizes reason and virtue. The wish king Samantabhadra Bodhisattva rides a white elephant and carries the white lotus to give the truth to the world and fulfill the world's wishes, and making the whiteness deeply rooted in the hearts of the people. Therefore, white is worn by candidates, jinshi and the highest intellectuals, and they are also dubbed the "Kugy of the White". Government officials also like to wear white robes when entertaining guests and traveling. The characters who ride for leisure in the "traveling and riding" in the Tang Dynasty are dressed in white robes. The color of women's clothing in Tang Dynasty should follow the color of their husbands or their children, so the white has become a common color of women's clothing. The women's tippet is commonly white long belts, pursuing the elegant and ethereal, enchanting and graceful feeling of Buddha. Yellow, with its pure and beautiful brightness, brings people sunshine-like appeal, which is considered to have the power to exorcise evil spirits. It is the noblest color of Buddhism, symbolizing the rareness of Buddhism, the sacredness of Buddha, and the balanced and unfixed middle way, so it was respected by Buddhism. The temple architecture and the Bodhisattva statues are often decorated with yellow ornaments and the Holy Monasteries also use yellow to make the Buddha statues manifest sacred and noble. Buddhist religious symbols also cast a mystery on the yellow color. Therefore, Tang Gaozu Wu De began to ban the folk from using yellow color, which has become a royal color that is used to boldly establish the imperial supremacy of the royal family and the appearance of domination.

In addition, under the open and inclusive atmosphere of the Tang Dynasty, although the costumes are mostly dark or light colors, there are also other bright colors in Buddhist art. From the binary color $\mathrm{Ru}$ skirt in beginning of the Tang Dynasty to the red skirt after the glorious age of Tang Dynasty, active and bold pursuit of color is inseparable from the worship to Buddha. Red, in Buddhism, represents the blessing force of Dharma practice, and indicates achievements and happiness, which is very much in line with Tang people's preference for red. In the Central Plains, the extracted red dye is mainly valerian. Along with the spread 
of Buddhism, exotic safflowers such as sudan and Catunaregam spinosa are also brought into the Central Plains. Pomegranate-colored red dress became the best $\mathrm{Ru}$ skirts with the longest popular time in Tang Dynasty. The poems such as "spring generates jade curtain, and flower decorates the pomegranate Skirt" "the beautiful young girl with pink cheek wears a pomegranate-colored skirt and sit on the horse like a peach blossom" [3]676. In Tang Dynasty indirectly reflects the preference of people in Tang Dynasty for red. Red also blends Buddhism's natural erotic beauty with the life and aesthetics of the Tang people, and advances the magnificent style change of Ru skirt in the Tang dynasty.

In the large number of relics unearthed from the Astana Tomb in Turpan, Xinjiang, China, only the unearthed silk fabrics showed as many as twenty different colors of red, yellow and blue. The picture "people of Dudu official worship the Buddha" in the Cave 130 of the Mogao Grottoes in Dunhuang also reflects the vivid and colorful feeling of Buddhism from the clothing of people in the Tang Dynasty.

Buddhism has feeling on all life beings and admires the natural and beautiful forms of life. They often endow color with symbolism and present them as symbols in Buddhist art forms such as Buddha statues, medicine forks, and animals and plants to realize their religious utilitarian purposes. This not only gives enlightenment to the status symbol and strengthening effect of imperial power, but also provides rich color choices for the development of costume culture in the Tang Dynasty.

\section{Buddhist Implications in the Patterns of Ru Skirt}

The pattern of clothing in the Tang Dynasty is rich and varied. In addition to flowers, birds, insects, birds and animals, Buddhist symbols and abstract patterns with Buddhist symbols are also common. The typical Buddhist imaginative images such as the Svastika, scroll, grass, and po-phase flowers were transplanted into the costumes, which not only added a sense of religious mystery, but also conveyed rich riches and good fortune. Among them, pophase flowers have abstractly collected the beautiful characteristics of Indian Buddhist holy flower lotus, Datang peony, and Persian pomegranate. It is presented in an overlapping, symmetrical and radiant manner, splendid and beautiful, with deep meaning. Lotus is not only a holy thing of Buddha, but also traditional flowers in Central Plain area. The characteristics of low-key, peaceful and quiet and noble holiness imply the unconventional realm of Buddhism's cycle of getting rid of the trouble of life and death, desires, and worries, which coincides with the feelings of Central Plains symbolizing the noble quality by lotus, so the pattern of lotus is loved by people. The floral scrolls pattern with honeysuckle as an abstract matrix heralds the doctrine of continuous life-and-death cycles. Its shape is integrated with the traditional flow moire pattern in the Central Plains region, and has become one of the most representative motifs after fusion, which is loved by the Tang people. In addition, the cultural life and artistic elements of a large number of different regions such as Greece, Rome, India, and Iran absorbed in the development of Buddhism have also formed different patterns and was brought into China, integrating into the printing, dyeing and embroidery techniques of the Tang Dynasty, such as lions, elephants, camels, peacocks and other rare birds and animals pattern, Svastika characters, vajry pestle and other dhammapala halidom patterns that are not common in Central Plain. That made the patterns of $\mathrm{Ru}$ skirt in Tang Dynasty fresh, free, diverse and mystical, and it gradually evolved into a novel, rich, dignified and unique Tang style.

\section{Accessories of Ru Skirt Affected by Buddhism}

Tippet is an important accessory of Tang Dynasty Ru skirt. In "History of Ancient Chinese Clothing", Mr. Zhou Xibao cited many ancient documents to describe the tippet, but did not make a final conclusion on the source. Some scholars have investigated and researched that tippet may belong to the dress elements of Persia in West Asia, and that Persian tippet is influenced by Greece. There are also comparisons between the tippet in the Tang Dynasty and the shawls worn by Assyrian and Babylon, the Palla by the Greek women, and the saris of the Indian women. However, it still can't be confirmed whether it is an imported product through comparisons in many ways such as size, wearing method, style, and material. Tippet appeared in Chinese murals during the period of the Southern and Northern Dynasties. It was a kind of costume accessories like scarves and shawls. From the descriptions in ancient Chinese literature, mural and scroll paintings in Sui and Tang Dynasties, the basic style and wearing method of tippet can also be seen. At first, it was wide and thick to keep warm. After the Sui and Tang Dynasties, the changes were intense. Influenced by prosperous Buddhist culture, and elegant Buddha statues, before and after Tianbao Year (AD 742-756), it became lighter, thinner, more transparent, and longer, adding the elegant and luxurious decorative characteristics. The social meaning and purpose of use has changed from practicability to decoration.

Conophytum pucillum, originated in the South Asian subcontinent, was an aristocratic jewelry. Its Sanskrit means is "jewelry made of pearls". Conophytum pucillum is actual situation not just a string of pearls. The "Lotus Lotus Sutra" records that conophytum pucillum uses seven treasures of gold, silver, colored glaze, tridacna, agate, pearl, and rose as the materials, implying "immeasurably bright." Conophytum pucillum was introduced into China with the introduction of Buddhism into the East, this kind of common decoration of the Buddha's neck in Indian Buddhism was imitated and improved by women in the Tang Dynasty with economic and social prosperity, the development of the shape was much exaggerated, and the splendor of jewels and luxury feeling was doubled. It is common in the major ceremonial activities reflected in the murals. With the wide sleeves of the Ru skirt, the figures are dignified and graceful, with gorgeous and noble charm. It is also commonly seen in the maids and dancer in Tang dynasty to show the graceful and beautiful posture.

\section{CONCLUSION}

Buddhism was originated in ancient India and travelled to China along the Silk Road through Central Asia and was 
localized. It became a medium for cultural exchanges between China and the West. Buddhism flourished with the prosperity and development of Tang dynasty, and declined with the decline of the Tang dynasty. Apart from its political interaction with the Tang dynasty, it had a far-reaching impact on Chinese social life, ideology and culture, etiquette and customs. For a long time, the characters of the Tang Dynasty's figures were summed up as "regarding fat as beauty" and sexy and open. The author believes that this is not accidental. On the one hand, it is based on the condition of socio-political and economic opening at that time. On the other hand, based on the foreign cultural drive carried by Buddhism, such an unprecedented aesthetic features and vanguard style can be formed. From the beginning of the Tang Dynasty, Ru skirts gradually began to be beautiful and luxury from the plain and simple style in Sui Dynasty, showing the colorful, exposed, harmonious, elegant, and open characteristic, which reflects the scene of the development of flourishing age, but also highlights the vitality of Buddhist art. Since ancient times, China has become a country of clothing. It often uses styling art to convey etiquette and national spiritual culture. $\mathrm{Ru}$ skirts in Tang dynasty, as a concrete manifestation of the carrier and thought of cultural heritage, are deeply influenced and infiltrated by Buddhist arts. It retains the native traditions when absorbing the exotic colors brought by Buddhism. Its change is a kind of adherence to local culture under the influence of Westernization, as well as a comprehensive application of foreign culture. This not only shows the Chinese people's inclusiveness in the context of different national conditions since ancient times, but also reveals how people in today's world can adopt ideas, attitudes, and make innovations in their openness and exchanges. These are good reference for the people's aesthetic concepts, artistic thought and modeling theory and method.

\section{REFERENCES}

[1] Xie Shan. Study of the Rise and Decline of Buddhism in Tang Dynasty [D]. Henan University. 2014. 谢山.唐代佛教兴衰研究[D]. 河南大学. 2014

[2] Xie Chengshui. The Formation of the Ideal Beauty of Buddhist Statues in Tang Dynasty[J]. Dunhuang Reseach. 2001, no.3. 谢成水. 唐代佛教造像理想美的形成 $[\mathrm{J}]$.敦煌研究.2001,第三期

[3] Lin Debao. Detailed Notes for Collected Tang Poems [M]. Dalian: Dalian Publishing House, 1997. 林德保.祥注全唐诗[M].大连：大连 出版社, 1997

[4] Zhou Jingbao. The Body Art in the Silk Road and Ancient Chinese Xinjiang Murals [J] Hundred Schools in Arts, Issue 2, 2011. 周菁葆. 丝绸之路与中国古代新疆壁画中的人体艺术 [J]艺术百家, 2011 第 二期.

[5] Zhou Xibao. Ancient Chinese Costume History [M]. Beijing: Central Compilation\&Translation Press, 2011. 周锡保.中国古代服装史[M]. 北京: 中央编译出版社, 2011

[6] Cao Zhe. Research on the Tang Dynasty Costume History Based on Dunhuang fresco[D]. Donghua University, 2008. 曹喆. 以敦煌壁画 为主材料的唐代服饰史研究[D]. 东华大学, 2008.

[7] Zou Jing. The Influence of Buddhism on the Costume Culture of the Tang Dynasty [D]. Hunan University of Technology, 2009. 邹婧. 佛 教对唐代服饰文化的影响 [D].湖南工业大学, 2009 . 